\title{
A COMPLEX THREE-UNIT PARALLEL SYSTEM WITH PREPARATION TIME FOR REPAIR
}

\author{
Y.A. Mwanga ${ }^{1}$, J.W. Joubert ${ }^{2,3}$ and V.S.S Yadavalli ${ }^{4}$ \\ ${ }^{1}$ Institute of Statistics and Applied Economics \\ Makerere University, Uganda \\ ymwanga@isae.mak.ac.ug \\ ${ }^{2,4}$ Department of Industrial \& Systems Engineering \\ University of Pretoria, South Africa \\ ${ }^{2}$ johan.joubert@up.ac.za, ${ }^{4}$ sarma.yadavalli@up.ac.za \\ ${ }^{3}$ Built Environment \\ Council for Scientific and Industrial Research (CSIR), South Africa \\ joubert@csir.co.za
}

\begin{abstract}
It is reasonable to expect that preparation time is needed to ready a repair facility before a repair can be carried out. A three-unit system with a 'preparation time' for the repair facility is studied in this paper. The steady-state availability of such a system is obtained. The asymptotic confidence limits of the steady state availability are obtained numerically.

\section{OPSOMMING}

Redelikerwys kan verwag word dat ' $n$ herstelproses voorafgegaan word deur ' $n$ voorbereidingsproses voordat herstel ' $n$ aanvang kan neem. ' $n$ Sisteem wat bestaan uit drie eenhede waar ' $n$ sodanige voorbereidingsproses voor herstelwerk moet plaasvind word ondersoek. Die gestadigde stelselbeskikbaarheid met asimptotiese vertrouegrense word numeries blootgestel.
\end{abstract}




\section{INTRODUCTION}

Reliability theory is a very important branch of systems engineering and operations research and deals with methods of evaluating the various measures of performance of a system that may be subject to gradual deterioration. Any systems analysis, in order to be complete, must give due consideration to system reliability. Multiple unit systems have attracted the attention of many applied probabilists and reliability engineers for their applicability in their respective fields. Kistner and Subramanian [5] considered an $n$-unit warm standby redundant system with a single repair facility. In this case, the probability density function of the life time of the online unit was assumed to be arbitrary while all the other distributions are exponential; these results were later extended by Subramanian, Venkatakrishnan and Kistner [11]. Gupta and Bansal [3] studied the cost benefit analysis of a single server three unit redundant system with inspection, delayed replacement and two types of repair. A multiple component system in which $\mathrm{n}$ identical units connected in series are needed for the system to function, the units being supported by $\mathrm{m}$ spares and a single repair facility, Gupta and Bansal [3] have analyzed a cost function for a three unit standby system subject to random shocks and linearly increasing failure rates. The study of $n$-unit systems, even in the case of cold standbys, appears to be rather complicated. Sarma and Parvez [10] studied a three unit system in which all the distributions assumed are discrete. Muller [7] studied a three unit standby system when the life-times and repair time distributions are assumed to be arbitrary and obtained the expressions for reliability and availability. From the above literature, it is clear that all the models have the assumption that the repair facility is continuously available to attend to the repair of the failed units (Kistner and Subramanian [5], Krishnamoorthy et al [6], Bon and Paltanea [1], Frostig and Levikson [2] and Ke and Pearn [4]. But it is reasonable to expect that a preparation time might be needed to get the repair facility ready before the next repair could be taken up. If this preparation time is started only when a unit arrives for repair, it is easy to solve the problem, since the preparation time plus the actual repair time may be taken as the total repair time. But this preparation time usually starts immediately after each repair completion, so that the facility becomes available at the earliest. In this paper a threeunit standby redundant system is studied in which the preparation time has been introduced (Sarma [9]; Yadavalli et al [13], [14]). Asymptotic confidence limits for the steady state availability are also obtained. The numerical results are presented for the system measures in the last section.

\section{SYSTEM DESCRIPTION}

a. The system consists of three identical units connected in parallel. Either unit performs the system function satisfactorily.

b. There is only one repair facility. Each unit is new after repair.

c. At $\mathrm{t}=0$, all the units are new and the repair facility is available.

d. After each repair completion, the repair facility is not available for a random time which is called the 'preparation time.

e. The life time, repair time and the preparation time are independent random variables and assumed to have an exponential distribution with parameters $\lambda, \mu$, and Y respectively.

\section{AVAILABILITY ANALYSIS}

Consider the state of the system to be $(i, j)$, where $i$ is the number of failed units, and $j$ is the state of the repair facility such that $j=0$ represents that the repair facility is available and $j=1$ represents that the repair facility is unavailable. The state transitions are presented in Table 1. 
When $\mathrm{n}=3$, the possible transitions are presented in Table 2 .

\begin{tabular}{|c|c|c|}
\hline \multicolumn{2}{|c|}{ State } & \\
\hline From & To & Rate \\
\hline $\begin{array}{l}(i, 0) \\
(i, 0) \\
(i, 1) \\
(i, 1)\end{array}$ & $\begin{array}{l}(i+1,0) \\
(i-1,0) \\
(i, 0) \\
(i+1,1)\end{array}$ & $\begin{array}{ll}(\mathrm{n}-\mathrm{i}) \lambda, & \mathrm{i}=\{0,1, \ldots, \mathrm{n}-1\} \\
\mu, & \mathrm{i}=\{0,1, \ldots, \mathrm{n}\} \\
\mathrm{\gamma}, & \mathrm{i}=\{0,1, \ldots, \mathrm{n}\} \\
(\mathrm{n}-\mathrm{i}) \lambda, & \mathrm{i}=\{0,1, \ldots, \mathrm{n}-1\}\end{array}$ \\
\hline
\end{tabular}

Table 1: State Transitions

\begin{tabular}{|c|c|c|}
\hline \multicolumn{1}{|c|}{ State } & To & Rate \\
\hline From & $(1,0)$ & $3 \lambda$ \\
$(0,0)$ & $(0,0)$ & $\gamma$ \\
$(0,1)$ & $(2,0)$ & $2 \lambda$ \\
$(1,0)$ & $(0,1)$ & $\mu$ \\
$(1,0)$ & $(1,0)$ & $3 \lambda$ \\
$(0,0)$ & $(1,0)$ & $\gamma$ \\
$(1,1)$ & $(3,0)$ & $\lambda$ \\
$(2,0)$ & $(1,1)$ & $\mu$ \\
$(2,0)$ & $(2,0)$ & $2 \lambda$ \\
$(1,0)$ & $(2,0)$ & $\gamma$ \\
$(2,1)$ & $(2,1)$ & $3 \mu$ \\
$(3,0)$ & $(3,0)$ & $\lambda$ \\
\hline
\end{tabular}

Table 2: State transitions for $\mathrm{n}=3$

Figure 1 illustrates the possible states of the 3-unit system at any time and also the transition intensities. The balance equations are derived for the steady-state probabilities for the number of failed units in the system.

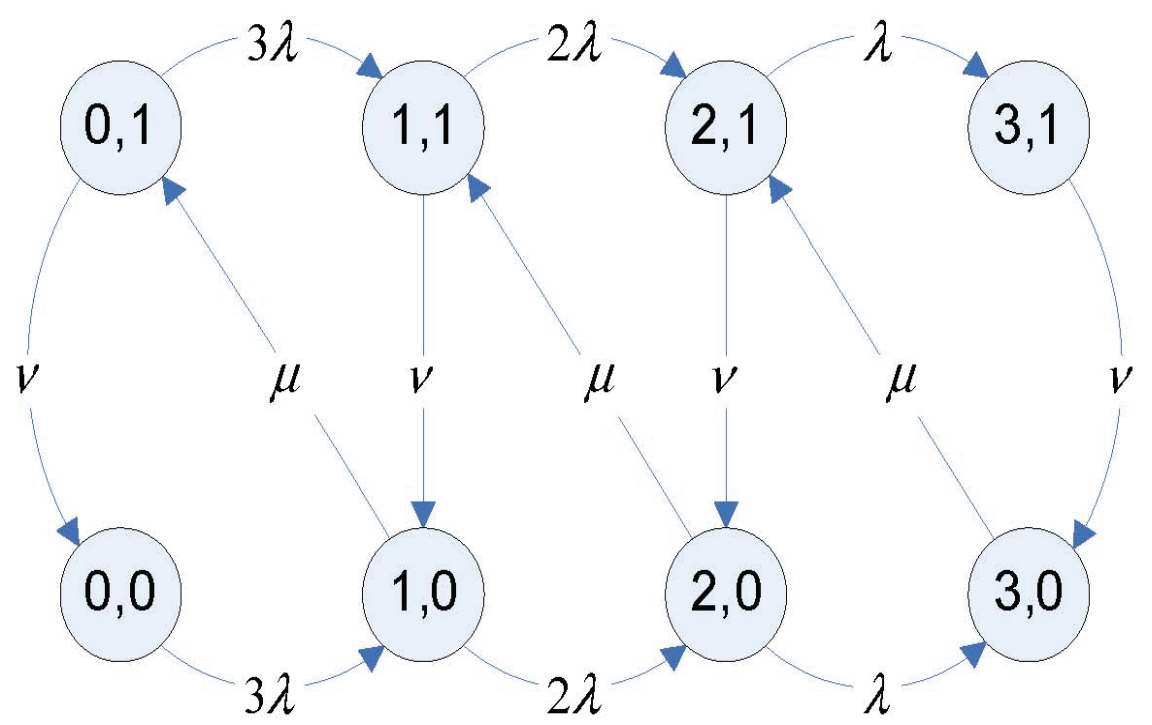

Figure 1: State transition diagram of a 3-unit system 
Let

$N(t) \equiv$ Number of failed units at time $t$.

$\mathrm{R}(\mathrm{t}) \equiv$ State of the repair facility at time $\mathrm{t}$.

Then $\{\mathrm{N}(\mathrm{t}), \mathrm{R}(\mathrm{t})\}$ is a continuous time Markov process with the state space

$S=\{(i, j) ; i=1,2,3 ; j=0,1\}$.

Let

$P_{i j}(t)=P[N(t)=i, R(t)=j]$

$p_{00}^{\prime}(t)=-3 \lambda p_{00}(t)+\gamma p_{01}(t)$

$p_{10}^{\prime}(t)=-(2 \lambda+\mu) p_{10}(t)+3 \lambda p_{00}(t)+\gamma p_{11}(t)$

$p_{20}^{\prime}(t)=-(\lambda+\mu) p_{20}(t)+2 \lambda p_{10}(t)+\gamma p_{21}(t)$

$p_{30}^{\prime}(t)=-\mu p_{30}(t)+\lambda p_{20}(t)+\gamma p_{31}(t)$

$p_{01}^{\prime}(t)=-(3 \lambda+\gamma) p_{01}(t)+\mu p_{10}(t)$

$p_{11}^{\prime}(t)=-(2 \lambda+\gamma) p_{11}(t)+3 \lambda p_{01}(t)+\mu p_{20}(t)$

$p_{21}^{\prime}(t)=-(\lambda+\gamma) p_{21}(t)+2 \lambda p_{11}(t)+\mu p_{30}(t)$

$p_{31}^{\prime}(t)=-\gamma p_{31}(t)+\lambda p_{21}(t)$

In the steady-state

$$
p_{i j}=\lim _{t} P[N(t)=i, R(t)=j]
$$

Using (9), the steady-state equations for $\mathrm{p}_{\mathrm{ij}}$ can be obtained as follows.

$3 \lambda p_{00}=\gamma p_{01}$

$(2 \lambda+\mu) p_{10}=3 \lambda p_{00}+\gamma p_{11}$

$(\lambda+\mu) p_{20}=2 \lambda p_{10}+\gamma p_{21}$

$\mu p_{30}=\lambda p_{20}+\gamma p_{31}$

$(3 \lambda+\gamma) p_{01}=\mu p_{10}$

$(2 \lambda+\gamma) p_{11}=3 \lambda p_{01}+\mu p_{20}$

$(\lambda+\gamma) p_{21}=2 \lambda p_{11}+\mu p_{30}$

$\gamma p_{31}=\lambda p_{21}$

Since the system is operable in states $(1,0),(0,0),(2,0),(0,1),(1,1)$, and $(2,1)$, the steadystate availability of the system is given by

$$
A_{\infty}=\sum_{n-0}^{2}\left(p_{n o}+p_{n 1}\right)
$$




\section{ESTIMATES FOR STEADY-STATE PROBABILITIES AND SYSTEM PERFORMANCE MEASURES}

Let $X_{1}, X_{2}, \ldots, X_{n}$ be a random sample of failure times for operating units with probability density function (pdf)

$$
f_{1}(x)=\lambda e^{-\lambda x} \quad \mathrm{x}>0 ; \lambda>0 .
$$

Let $Y_{1}, Y_{2}, \ldots, Y_{n}$ be a random sample of repair times of the failed units with pdf $f_{2}(y)=\mu e^{-\mu y} \quad y>0 ; \mu>0$.

Let $\mathrm{Z}_{1}, \mathrm{Z}_{2}, \ldots, \mathrm{Z}_{\mathrm{n}}$ be a sample of preparation times of the repair facility with pdf

$$
f_{3}(z)=\gamma e^{-\gamma z} \quad \mathrm{z}>0 ; \gamma>0 \text {. }
$$

Let $\bar{X}, \bar{Y}, \bar{Z}$ be the sample means of the time to failure for the operating unit, the time to repair for the failed units, and the time to preparation for the repair facility respectively.

Then $E(\bar{X})=\frac{1}{\lambda}, E(\bar{Y})=\frac{1}{\mu}$ and $E(\bar{Z})=\frac{1}{\gamma}$. It can be easily shown that $\bar{X}, \bar{Y}$ and $\bar{Z}$ are the maximum likelihood estimates of $\frac{1}{\lambda}, \frac{1}{\mu}$ and $\frac{1}{\gamma}$ respectively.

Furthermore, let $\hat{p}_{i j}$ be estimators of $p_{i j}$. The estimator of $A_{\infty}$ can now be obtained through

$$
\hat{A}_{\infty}=\sum_{n-0}^{2}\left(\hat{p}_{n 0}+\hat{p}_{n 1}\right)
$$

\section{ASYMPTOTIC COFIDENCE LIMITS FOR THE AVAILABILITY}

From the discussion in the previous section, $\hat{A}_{\infty}$ is a real-valued function in $\bar{X}, \bar{Y}, \bar{Z}$, which is also differentiable using the application of the multivariate central limit theorem due to Rao [8], it follows that

$$
\sqrt{n}\left[(X, Y, Z)-\left(\theta_{1}, \theta_{2}, \theta_{3}\right)\right] \text { converges to } \mathrm{N}_{3}(0, \Sigma) \text { in the distribution as } \mathrm{n} \rightarrow \infty \text {. }
$$

Where the dispersion matrix

$$
\Sigma=\left[\sigma_{i j}^{2}\right]_{3 \times 3}
$$

is given by

$$
\Sigma=\operatorname{diag}\left\lfloor\theta_{1}^{2}, \theta_{2}^{2}, \theta_{3}^{2}\right\rfloor,
$$

using the results by Rao [8], it follows that

$$
\left.\sqrt{n} \mid \hat{A}_{\infty}-A_{\infty}\right\rfloor \stackrel{D}{\longrightarrow} N_{3}\left(0, \sigma_{1}^{2}(\theta)\right)
$$


as $\mathrm{n} \rightarrow \infty$ with

$$
\sigma_{1}^{2}(\theta)=\sum_{i=1}^{3}\left[\frac{\partial A_{\infty}}{\partial \theta_{i}}\right]^{2} \delta_{i i}
$$

where

$$
\theta=\left(\theta_{1}, \theta_{2}, \theta_{3}\right)
$$

Let $\sigma_{1}^{2}(\hat{\theta})$ be the estimator for $\sigma_{1}^{2}(\theta)$ which is obtained by replacing $\theta$ by a consistent estimator $\hat{\theta}=(\overline{\mathrm{X}}, \overline{\mathrm{Y}}, \overline{\mathrm{Z}})$. Since $\sigma_{1}^{2}(\theta)$ is a continuous function of $\theta, \sigma_{1}^{2}(\hat{\theta})$ is a consistent estimator of $\sigma_{1}^{2}(\theta)[12]$.

Therefore,

$\sigma_{1}^{2}(\hat{\theta}) \rightarrow \sigma_{1}^{2}(\theta)$

as $n \rightarrow \infty$. Slutzky's theorem gives

$$
\frac{\sqrt{n}\left[\hat{A}_{\infty}-A_{\infty}\right\rfloor}{\sigma_{1}^{2}(\hat{\theta})} \stackrel{D}{\longrightarrow} N(0,1)
$$

as $n \rightarrow \infty$, which leads to

$$
P\left[-Z_{\frac{\alpha}{2}} \leq \frac{\sqrt{n}\left[\hat{A}_{\infty}-A_{\infty}\right]}{\sigma_{1}^{2}(\theta)} \leq Z_{\frac{\alpha}{2}}\right]=1-\alpha
$$

where $Z_{\frac{\alpha}{2}}$ is determined from standard normal tables or statistical software packages. Hence, the asymptotic $100(1-a) \%$ confidence limits for $A_{\infty}$ are given by $\hat{A}_{\infty} \pm Z_{\frac{\alpha}{2}} \frac{\delta(\hat{\theta})}{\sqrt{n}}$. 


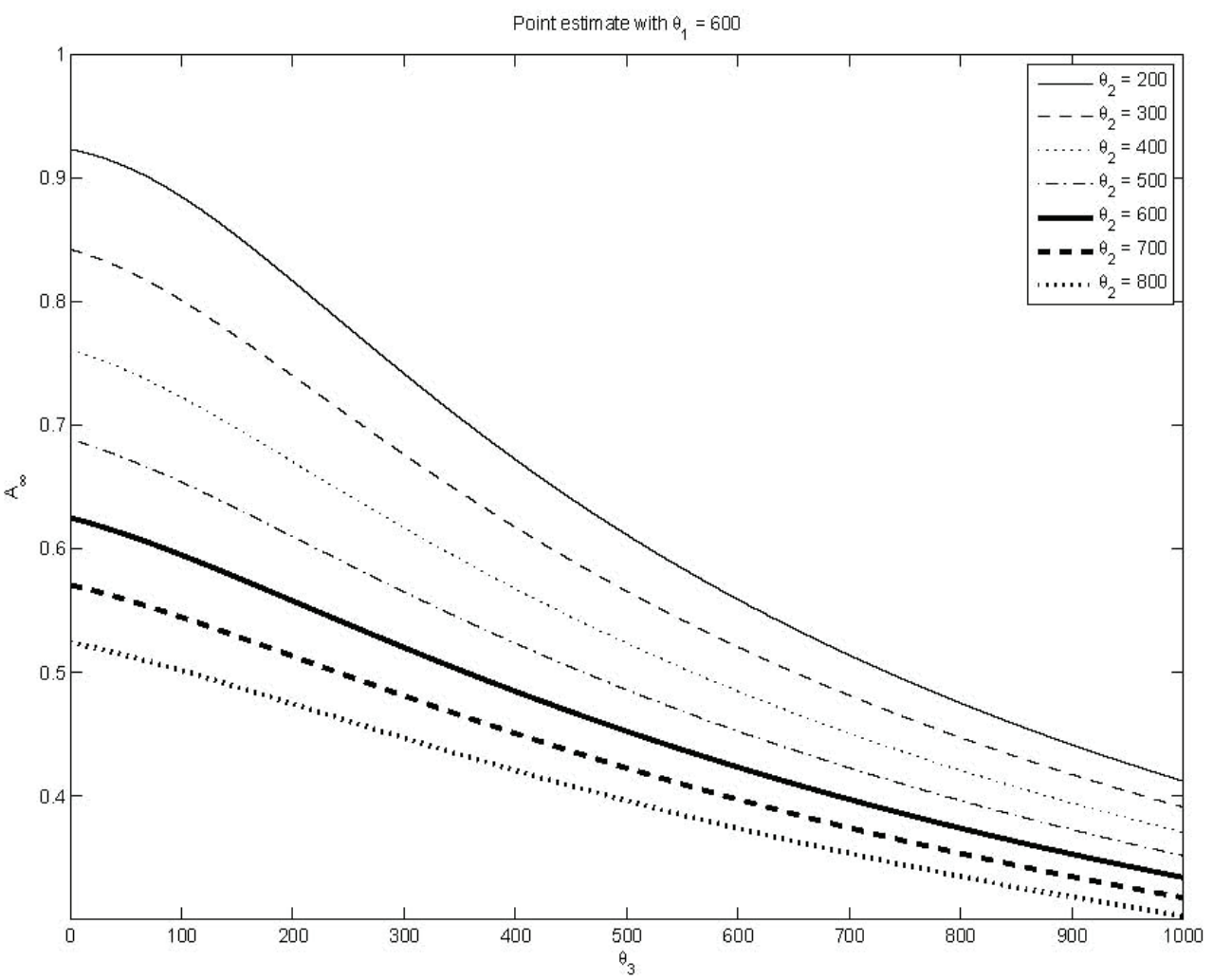

Figure 2: Steady state availability for changing repair time

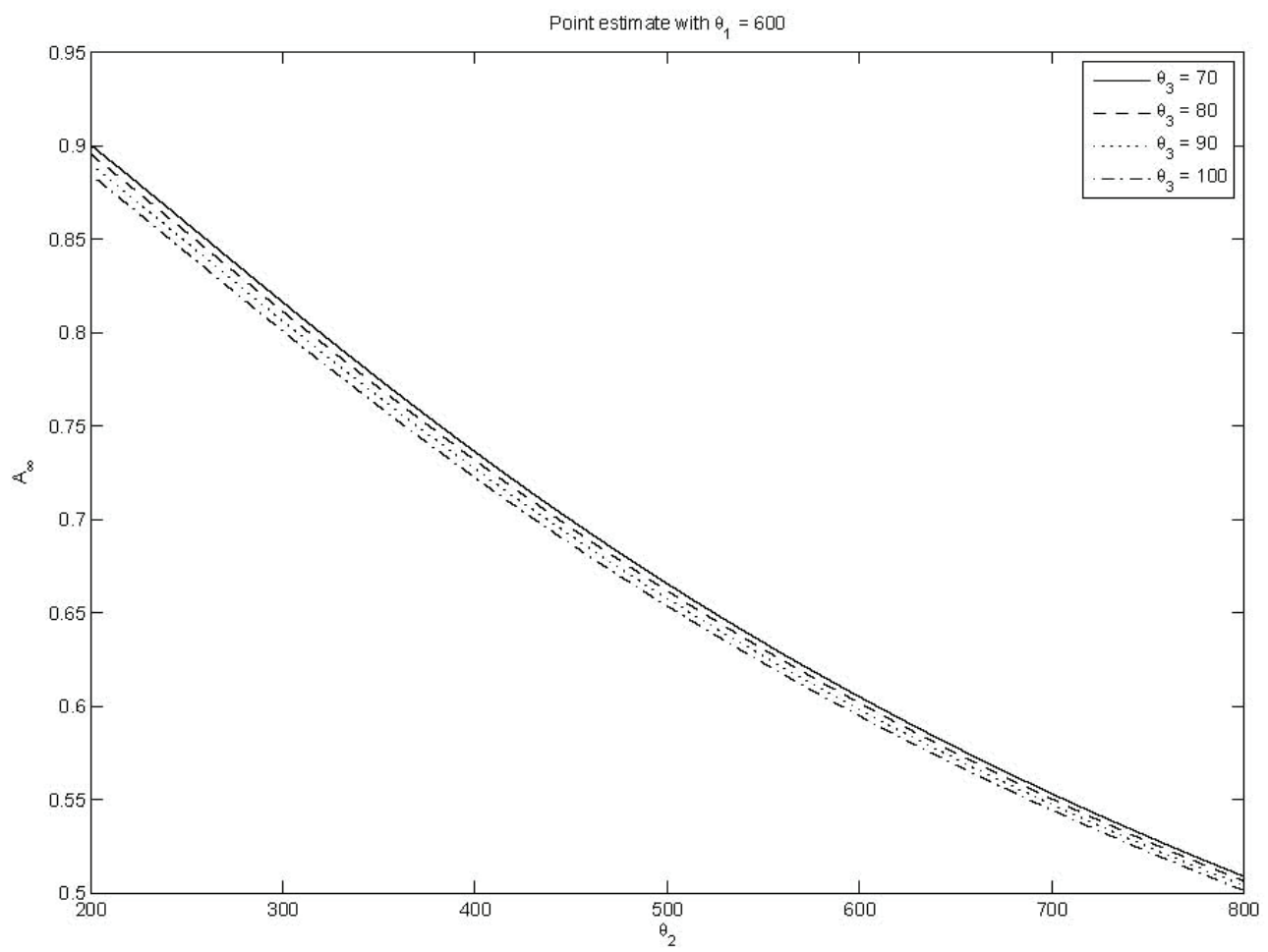




\begin{tabular}{|c|c|c|c|c|c|c|c|c|c|}
\hline \multirow[b]{2}{*}{$\mathrm{n}$} & \multirow[b]{2}{*}{$\theta_{2}$} & \multicolumn{8}{|c|}{$\theta$} \\
\hline & & \multicolumn{2}{|c|}{70} & \multicolumn{2}{|c|}{80} & \multicolumn{2}{|c|}{90} & \multicolumn{2}{|c|}{100} \\
\hline 100 & $\begin{array}{l}200 \\
300 \\
400 \\
500 \\
600 \\
700 \\
800\end{array}$ & $\begin{array}{l}0.8499 \\
0.7415 \\
0.6478 \\
0.5710 \\
0.5087 \\
0.4577 \\
0.4155\end{array}$ & $\begin{array}{l}0.9509 \\
0.8909 \\
0.8245 \\
0.7602 \\
0.7014 \\
0.6489 \\
0.6024\end{array}$ & $\begin{array}{l}0.8433 \\
0.7357 \\
0.6430 \\
0.5672 \\
0.5056 \\
0.4552 \\
0.4134\end{array}$ & $\begin{array}{l}0.9476 \\
0.8869 \\
0.8203 \\
0.7563 \\
0.6978 \\
0.6457 \\
0.5996\end{array}$ & $\begin{array}{l}0.8363 \\
0.7297 \\
0.6381 \\
0.5633 \\
0.5024 \\
0.4526 \\
0.4113\end{array}$ & $\begin{array}{l}0.9441 \\
0.8826 \\
0.8160 \\
0.7522 \\
0.6942 \\
0.6424 \\
0.5967\end{array}$ & $\begin{array}{l}0.8290 \\
0.7234 \\
0.6331 \\
0.5593 \\
0.4992 \\
0.4500 \\
0.4091\end{array}$ & $\begin{array}{l}0.9402 \\
0.8781 \\
0.8115 \\
0.7481 \\
0.6904 \\
0.6391 \\
0.5938\end{array}$ \\
\hline 200 & $\begin{array}{l}200 \\
300 \\
400 \\
500 \\
600 \\
700 \\
800\end{array}$ & $\begin{array}{l}0.8646 \\
0.7634 \\
0.6736 \\
0.5987 \\
0.5369 \\
0.4857 \\
0.4429\end{array}$ & $\begin{array}{l}0.9361 \\
0.8690 \\
0.7986 \\
0.7325 \\
0.6731 \\
0.6209 \\
0.5750\end{array}$ & $\begin{array}{l}0.8586 \\
0.7578 \\
0.6690 \\
0.5949 \\
0.5337 \\
0.4883 \\
0.4407\end{array}$ & $\begin{array}{l}0.9324 \\
0.8647 \\
0.7944 \\
0.7286 \\
0.6697 \\
0.6178 \\
0.5723\end{array}$ & $\begin{array}{l}0.8521 \\
0.7521 \\
0.6642 \\
0.5909 \\
0.5305 \\
0.4804 \\
0.4384\end{array}$ & $\begin{array}{l}0.9283 \\
0.8602 \\
0.7900 \\
0.7245 \\
0.6661 \\
0.6146 \\
0.5696\end{array}$ & $\begin{array}{l}0.8453 \\
0.7461 \\
0.6592 \\
0.5869 \\
0.5272 \\
0.4777 \\
0.4362\end{array}$ & $\begin{array}{l}0.9239 \\
0.8554 \\
0.7854 \\
0.7204 \\
0.6624 \\
0.6114 \\
0.5667\end{array}$ \\
\hline 1000 & $\begin{array}{l}200 \\
300 \\
400 \\
500 \\
600 \\
700 \\
800\end{array}$ & $\begin{array}{l}0.8844 \\
0.7926 \\
0.7082 \\
0.6357 \\
0.5745 \\
0.5230 \\
0.4794\end{array}$ & $\begin{array}{l}0.9163 \\
0.8398 \\
0.7661 \\
0.6955 \\
0.6355 \\
0.5835 \\
0.5385\end{array}$ & $\begin{array}{l}0.8790 \\
0.7874 \\
0.7036 \\
0.6318 \\
0.5713 \\
0.5203 \\
0.4771\end{array}$ & $\begin{array}{l}0.9120 \\
0.8352 \\
0.7597 \\
0.6916 \\
0.6321 \\
0.5835 \\
0.5359\end{array}$ & $\begin{array}{l}0.7819 \\
0.6989 \\
0.6279 \\
0.5680 \\
0.5203 \\
0.4747\end{array}$ & $\begin{array}{l}0.8303 \\
0.7552 \\
0.6876 \\
0.6286 \\
0.5805 \\
0.5333\end{array}$ & $\begin{array}{l}0.8670 \\
0.7763 \\
0.6941 \\
0.6238 \\
0.5646 \\
0.5175 \\
0.4722\end{array}$ & $\begin{array}{l}0.8252 \\
0.7505 \\
0.6835 \\
0.6250 \\
0.5744 \\
0.5306\end{array}$ \\
\hline
\end{tabular}

Table 3: $95 \%$ Confidence interval for $A_{\infty}, \theta_{1}=600$

Figure 3: Steady state availability for changing preparation time

\section{NUMERICAL ILLUSTRATION}

In this section, numerical results of steady-state availability, $A_{\infty}$ are given. Figure 2 illustrates the repair time $\left(\theta_{3}\right)$ vs $A_{\infty}$ for fixed failure and preparation times respectively, while Figure 3 illustrates the preparation time $\left(\theta_{2}\right)$ vs $A_{\infty}$ for fixed failure and repair time. From Figure 2 and 3 it is clear that for fixed $\theta_{1}$ as the repair time $\theta_{2}$ increases, $A_{\infty}$ decreases. Also, for a fixed $\theta_{1}, A_{\infty}$ decreases as the preparation time $\theta_{3}$ increases. Tables 3 and 4 present the confidence limits (both at $95 \%$ and $99 \%$ ) for different sample sizes. It is observed that, when $\mathrm{n}$ increases, the steady-state availability increases.

\section{CONCLUSIONS}

This paper develops the evaluation of availability using the difference differential equations for the state probabilities, for a three-unit complex system. The introduction of preparation time for the repair facility makes the system more complex.

The effects of various parameters on the system availability are numerically analyzed. Finally the sensitivity of system availability at specific values of parameters is examined. The numerical investigations indicate that as the preparation time increases the steady-state availability decreases this also holds for the repair time. The confidence limits for different parameters are obtained for different sample sizes. The results indicate that, when the sample size increases the availability increases, which is reasonable. For future study, non-Markovian models can be considered with the same and other assumptions 


\begin{tabular}{|l|l|l|l|l|l|l|l|l|l|}
\hline \multirow{5}{*}{$\mathrm{n}$} & & \multicolumn{7}{|c|}{$\theta_{3}$} \\
\cline { 2 - 9 } & $\theta_{2}$ & \multicolumn{2}{|c|}{70} & \multicolumn{2}{|c|}{80} & \multicolumn{2}{c|}{90} & \multicolumn{2}{c|}{100} \\
\hline \multirow{5}{*}{100} & 200 & 0.8344 & 0.9664 & 0.8274 & 0.9636 & 0.8199 & 0.9606 & 0.8120 & 0.9573 \\
& 300 & 0.7186 & 0.9138 & 0.7126 & 0.9100 & 0.7063 & 0.9060 & 0.6998 & 0.9017 \\
& 400 & 0.6207 & 0.8516 & 0.6159 & 0.8475 & 0.6109 & 0.8432 & 0.6058 & 0.8388 \\
& 500 & 0.5420 & 0.7891 & 0.5382 & 0.7852 & 0.5634 & 0.7811 & 0.5304 & 0.7769 \\
& 600 & 0.4792 & 0.7309 & 0.4762 & 0.7272 & 0.4731 & 0.7235 & 0.4699 & 0.7197 \\
& 700 & 0.4284 & 0.6781 & 0.4260 & 0.6748 & 0.4235 & 0.6715 & 0.4210 & 0.6681 \\
& 800 & 0.3869 & 0.6310 & 0.3849 & 0.6281 & 0.3829 & 0.6251 & 0.3808 & 0.6220 \\
& & & & & & & & & \\
\hline \multirow{5}{*}{200} & 200 & 0.8537 & 0.9470 & 0.8734 & 0.9436 & 0.8405 & 0.9400 & 0.8320 & 0.9360 \\
& 300 & 0.7472 & 0.8852 & 0.7415 & 0.8811 & 0.7355 & 0.8767 & 0.7293 & 0.8722 \\
& 400 & 0.6545 & 0.8177 & 0.6498 & 0.8136 & 0.6449 & 0.8092 & 0.6399 & 0.8047 \\
& 500 & 0.5782 & 0.7530 & 0.5744 & 0.7490 & 0.5705 & 0.7450 & 0.5665 & 0.7408 \\
& 600 & 0.5160 & 0.6940 & 0.5129 & 0.6905 & 0.5098 & 0.6868 & 0.5065 & 0.6831 \\
& 700 & 0.4650 & 0.6416 & 0.4624 & 0.6384 & 0.4598 & 0.6352 & 0.5272 & 0.6319 \\
& 800 & 0.4226 & 0.5953 & 0.4205 & 0.5925 & 0.4184 & 0.5896 & 0.4162 & 0.5867 \\
& & & & & & & & & \\
\hline \multirow{5}{*}{1000} & 200 & 0.8795 & 0.9212 & 0.8739 & 0.9170 & 0.8680 & 0.9125 & 0.8616 & 0.9076 \\
& 300 & 0.7853 & 0.8471 & 0.7801 & 0.8425 & 0.7745 & 0.8377 & 0.7688 & 0.8327 \\
& 400 & 0.6996 & 0.7726 & 0.6951 & 0.7683 & 0.6903 & 0.7638 & 0.6855 & 0.7592 \\
& 500 & 0.6265 & 0.7047 & 0.6227 & 0.7008 & 0.6187 & 0.6968 & 0.6147 & 0.6927 \\
& 600 & 0.5652 & 0.6448 & 0.5620 & 0.6414 & 0.5587 & 0.6379 & 0.5553 & 0.6343 \\
& 700 & 0.5138 & 0.5928 & 0.5111 & 0.5898 & 0.5083 & 0.5867 & 0.5055 & 0.5836 \\
& 800 & 0.4704 & 0.5476 & 0.4681 & 0.5450 & 0.4657 & 0.5423 & 0.4633 & 0.5396 \\
& & & & & & & & & \\
\hline
\end{tabular}

Table 4: $99 \%$ Confidence interval for $A_{\infty}, \theta_{1}=600$

\section{REFERENCES}

[1] Bon, J.L. and \& Paltanea, B. 2000. Convergence of the number of failed components in a Markov system with non-identical components, Journal of Applied Probability, 38(4), pp. 882-897.

[2] Frostig, E. and Levikson, B. 2002. On the availability of $\mathrm{R}$ out of $\mathrm{N}$ repairable systems, Naval Research Logistics Quarterly, 49(5), pp. 483-498.

[3] Gupta, R. and Bansal, S. 1991. Cost analysis of a three-unit standby system subject to random shocks and linearly increasing failure rates, Reliability Engineering and System Safety, 33(2), pp. 249-263.

[4] Ke, J.C. and Pearn, W.L. 2004. Optimal management policy for heterogeneous arrival queueing systems with server breakdown and vacations, Quality,Technology and Quantitative Management, 1, pp. 149-162.

[5] Kistner, K.P. and Subramanian, R. 1974. Die Zuverlassigkeit eines systems mit redundant storanfalligen Komponenten und Reparaturmoglichkeiten, Zeitschrift fur Operations Research, 18, pp. 117-129.

[6] Krishnamoorthy, A., Ushakumari, P.V. and Lakshmy, B. 2002. k out of $n$ system with repair, the N policy, Asia Pacific Journal of Operational Research, 19(1), pp. 47-61. 
[7] Muller, M.A.E. 2005. Probabilistic analysis of repairable redundant systems, PhD thesis, University of Pretoria, South Africa.

[8] Rao, C. R. 1973. Linear Statistical Inference and its Applications, John Wiley \& Sons, New York.

[9] Sarma, Y.V.S. 1982. Stochastic models of redundant repairable systems, Ph.D thesis, India Institute of Technology, India.

[10] Sarma, Y.V.S. and Parvez, M. 1984. A complex three unit system, Microelectronics and Reliability, 24(4), pp. 661-662

[11] Subramanian, R., Venkatakrishnan, K.S. and Kistner, K.P. 1976. Reliability of repairable systems with standby failure, Operations Research, 24(1), pp. 169-176.

[12] Wackerly, D.D., Mendenhall, W. and Scheaffer, R.L. 2002. Mathematical statistics with applications, Duxbury Press, Pacific Grove, CA.

[13] Yadavalli, V.S. S., Botha, M. and Bekker, A. 2002a. Asymptotic confidence limits for the steady state availability of a two-unit parallel system with 'preparation time' for the repair facility, Asia Pacific Journal of Operational Research, 19(2), pp. 249-256.

[14] Yadavalli, V.S.S., Botha, M. and Bekker, A. 2002b. Confidence limits for the steady state availability of a system with 'rest period' for the repair facility, Electronic Modelling, 24(5), pp. 99-103. 